\title{
Preemptive vessel dilator cricothyrotomy aids in the management of upper airway obstruction
}

\section{[Une crico-thyrotomie préventive réalisée avec un dilatateur vasculaire aide la} prise en charge de l'obstruction des voies aériennes supérieures]

James R. Boyce MD, ${ }^{*}$ Glenn E. Peters MD, $\dagger$ William R. Carroll MD, $\dagger$ J. Scott Magnuson MD,$\dagger$ Allison McCrory MD, $\dagger$ Arthur M. Boudreaux MD*

Purpose: Our objective was to demonstrate that preemptive vessel dilator cricothyrotomy may be useful when managing the patient with airway obstruction.

Methods: An Institutional Review Board approved retrospective study was undertaken in 88 patients for whom this technique was selected. The anesthesiologists and surgeons identified as authors were directly involved in the care of these patients. All vessel dilator cricothyrotomies were performed in the operating rooms of University Hospital, UAB, Medical Center. The patients selected for this airway management technique were afflicted with some type of supraglottic lesion, usually squamous cell carcinoma, which was obstructing their airways to an extent that complete airway obstruction during induction of anesthesia was a significant possibility.

Prior to induction of anesthesia, the vessel dilator was inserted into the tracheal lumen through the cricothyroid membrane as described. Oxygenation was maintained with jet ventilation from a Sanders jetting device. Age, sex, weight, initial and lowest $\mathrm{O}_{2}$ saturation, first recorded $\mathrm{ETCO}_{2}$, blood pressure and duration of jet ventilation were recorded.

Results: The airways were successfully managed in all 88 patients with this technique. There were no deaths, and no postoperative hypoxic sequelae; also complications were minor.

Conclusion: Vessel dilator cricothyrotomy as a preemptive procedure in the management of patients with significant supraglottic airway obstruction may be a useful addition to the anesthesiologists' armamentarium of airway management devices.

Objectif : Démontrer que la crico-thyrotomie préventive avec un dilatateur vasculaire peut aider la prise en charge d'une obstruction des voies respiratoires.

Méthode : Le comité d'examen a approuvé notre étude rétrospective auprès de 88 patients soumis à cette technique. Les anesthésiologistes et les chirurgiens, auteurs du présent article, ont été directement appelés à participer. Toutes les crico-thyrotomies avec dilatateur vasculaire ont été réalisées dans les salles d'opération du University Hospital, UAB, Medical Center. Les patients choisis présentaient une lésion oropharyngée, habituellement un épithéliome malpighien, qui obstruait les voies respiratoires de façon tellement étendue qu'une obstruction complète des voies aériennes était à craindre pendant l'induction de l'anesthésie. Avant l'induction, le dilatateur vasculaire a été inséré dans la lumière de la trachée par la membrane cricotyrö̈dienne. L'oxygénation a été maintenue avec la ventilation en jet par un appareil à jet Sanders. L'âge, le poids, la saturation initiale en $\mathrm{O}_{2}$ et la plus faible saturation, la première $\mathrm{ETCO}_{2}$ enregistrée, la tension artérielle et la durée de la ventilation en jet ont été notés.

Résultats : Les voies aériennes ont été bien protégées chez tous les patients. Il n'y a pas eu de décès ni de séquelles hypoxiques postopératoires, seulement des complications mineures.

Conclusion : La crico-thyrotomie avec dilatateur vasculaire, utilisée comme technique préventive chez des patients qui présentent une obstruction oropharyngée, peut s'ajouter avantageusement aux appareils de prise en charge des voies aériennes par les anesthésiologistes.

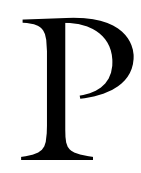

ATIENTS with supraglottic lesions obstructing the airway present several challenges. First, because of the tumour itself, airflow may be so impaired that effective mask ventilation is impossible. Secondly, sedation with benzodiazepines and/or opioids predisposes to increased airway compromise by compounding respiratory obstruction with respiratory depression. Also, supplemental oxygen may not improve hemoglobin

From the Department of Anesthesiology, ${ }^{*}$ and the Department of Surgery, $†$ University of Alabama at Birmingham Medical Center, Birmingham, Alabama, USA.

Address correspondence to: Dr. J.R. Boyce, UAB Medical Center, Department of Anesthesiology, 619 S. 19th St. Birmingham Al,

35249, USA. Phone: 205-934-7424; Fax: 205-975-1948; E-mail: jboyce@uab.edu

Accepted for publication January 20, 2005.

Revision accepted February 25, 2005. 
saturations because of low tidal volumes and the patient's resistance to accept oxygen by facemask or even nasal cannulae. Finally, standard induction of anesthesia with hypnotics, opioids and neuromuscular blockers, prior to securing the airway, is contraindicated because of total airway obstruction risks. When a full-blown "cannot ventilate; cannot intubate" situation is established, the outcome can be catastrophic for the patient. ${ }^{1}$

Otolaryngologists often choose to perform an awake emergency tracheotomy under local anesthesia to resolve this airway problem. However, this emergency airway management procedure has a reported complication rate two to five times higher than a controlled, elective tracheotomy. ${ }^{2,3}$ Many patients with severe airway obstruction cannot lie still in a supine or even back-up position throughout the procedure, compounding the difficulty of surgical access into the tracheal lumen.

The principle of preemptive cricothyrotomy, as a primary procedure, is to establish a method of oxygenation in these patients with difficult airways due to supraglottic obstruction thereby minimizing the risks of hypoxemia and maximizing the expedient successes of subsequent airway management techniques. This report describes our experience with an elective airway management technique, vessel dilator cricothyrotomy (VDCT), developed by the Department of Anesthesiology and the Division of Otolaryngology-Head and Neck Surgery at the University of Alabama at Birmingham. ${ }^{4}$

\section{Methods}

A retrospective chart review of 88 consecutive patients with either malignant or benign head or neck tumours and anesthetized during the study period of 19992004, using the VDCT procedure, was undertaken. Approval was obtained from the Institutional Review Board. Date of service, age and gender of patient, location and size of upper airway lesion, and subsequent airway management procedures after VDCT were recorded as was the duration of transtracheal ventilation, lowest $\mathrm{O}_{2}$ saturation, and any complications during or after the transtracheal ventilation.

\section{VDCT technique}

Patients were placed in a $30^{\circ}$ back-up position on the operating room table. Sedation (e.g., midazolam $2 \mathrm{mg}$ $i v$ and ketamine $20 \mathrm{mg} i v$ ) was administered, only after all surgical equipment was opened and both anesthesiologist and surgeon were present. Sedation was held until preparation was complete in the operating room to avoid any potential sedation-related airway compromise.
After routine monitors were applied, the anterior neck was prepped and draped. A small roll of towels was placed behind the neck allowing the head to extend, maximizing access to the cricothyroid membrane. Once sedated, patients frequently accepted supplemental oxygen administered by facemask or nasal cannula. A skin wheal over the cricothyroid membrane was made with $2 \%$ lidocaine using a $26 \mathrm{G}$, $5 / 8$ " needle on a $10 \mathrm{~mL}$ syringe. The same needle, directed caudally, was then used to puncture the cricothyroid membrane in the mid-saggital plane. One to $2 \mathrm{~mL}$ of lidocaine were injected into the tracheal lumen. Repeat cricothyroid membrane puncture was performed with a $14 \mathrm{G}$ catheter-over-needle assembly. When free aspiration of air confirmed correct placement, the catheter was advanced and the needle removed. After another test for free air aspiration and injection of additional lidocaine, the guide wire from the dilator set (Cook Critical Care, Bloomingtom, IN, USA.) was inserted into the tracheal lumen through the catheter. The 14-G catheter was removed and the distal end of the guide wire was positioned above the carina to avoid stimulation and coughing paroxysms. The 18-G vessel dilator was then advanced over the guide wire so that 4 to $6 \mathrm{~cm}$ of the dilator remained within the tracheal lumen. After removing the guide wire, correct catheter placement was confirmed by a final test of free air aspiration and connecting the gas sampling line from the circle system to detect end-tidal $\mathrm{CO}_{2}$. The vessel dilator, secured to the skin with adhesive tape, was then connected to a Sanders jetting device (Mannujet III VBM Medicintechnic, Lans, Germany) to administer oxygen into the tracheobronchial tree via jet ventilation. To minimize risks of barotrauma, the wall oxygen pressure in the noncompliant tubing of the jetting device was reduced with the in-line reducing valve from 55 to 25 to 30 pounds per square inch for the initial driving pressure. Chest excursion and egress, essential to minimize risks of over-inflation were monitored by watching for chest deflation and listening for sounds of exhalation at the patient's mouth (or with a stethoscope to the patient's larynx). The oxygen pressure was increased with the reducing valve as needed. At this point, heavy sedation or complete iv induction of anesthesia and full neuromuscular blockade with a nondepolarizing neuromuscular blocker (e.g., rocuronium) was achieved as the neuromuscular blockade increased jet ventilation became more effective. The jetting rate depended on the time required for egress, but 10 to 15 breaths. $\mathrm{min}^{-1}$ were average. 
TABLE

\begin{tabular}{ll}
\hline Parameter & Range (average) \\
\hline Age $(\mathrm{yr})$ & $39-80(57 \pm 12)$ \\
Weight $(\mathrm{kg})$ & $36-265(64.8 \pm 30)$ \\
$\mathrm{O}_{2}$ saturation (before VDCT) $(\%)$ & $30-95(88 \pm 12.1)$ \\
$\mathrm{O}_{2}$ saturation (during VDCT) $(\%)$ & $85-100(97.5 \pm 2.7)$ \\
& $\left(\mathrm{In} 79\right.$ patients: $\left.\mathrm{SpO}_{2}>95 \%\right)$ \\
Duration of jet ventilation $(\mathrm{min})$ & $2-66(16.9 \pm 10.4)$ \\
First measured ETCO2 $(\mathrm{mmHg})$ & $38-117(45 \pm 17.1)$ \\
\hline
\end{tabular}

Patient demographics, perioperative oxygen saturation, first endtidal $\mathrm{CO}_{2}$ levels after vessel dilator cricothyrotomy (VDCT) and duration of jet ventilation. Data presented with the ranges, averages and standard deviations.

\section{Results}

Of the 88 patients identified, 26 were females and 62 males with an average age of $57.3 \pm 12$ yr. The average weight was $64.8 \pm 30 \mathrm{~kg}$; (one morbidly obese patient who weighed $265 \mathrm{~kg}$, body mass index 89.5 , accounts for the large SD).

The average length of time that the VDCT was in place and used as the sole means of airway support was $16.9 \mathrm{~min} \pm 10.4$ (ranging from 2 to $66 \mathrm{~min}$ ). Of the 88 patients who had VDCT performed at the initiation of anesthesia, 66 were subsequently intubated, (58 of 66 had an orotracheal tube placed, and 8 nasal). Of these 66 patients, 27 were successfully extubated, 26 had a tracheotomy placed, and 13 had a laryngectomy with tracheostoma performed. Ten of the patients with an initial VDCT had a tracheotomy performed directly with one of the ten undergoing subsequent laryngectomy. Twelve of the 88 had the VDCT as the sole airway management throughout surgery. These patients underwent direct laryngoscopy with either biopsy or airway debridement with surgical microdebrider and were awakened with the vessel dilator in place. Once adequate airway patency was established, the vessel dilator was removed in the postanesthesia care unit (PACU) prior to transfer to the ward. The morbidly obese patient was successfully intubated by a second anesthesiologist during jet ventilation with VDCT; the lowest oxygen saturation in this patient was $87 \%$.

Oxygen saturations during jet ventilation ranged from $85 \%$ to $100 \%$ (Table). One patient was taken emergently to the operating room for tracheotomy to relieve airway obstruction. Prior to VDCT his oxygen saturation was $30 \%$ but remained above $92 \%$ with jet ventilation through the vessel dilator. Subsequent tracheotomy was performed under total iv anesthesia without incident (Figure).

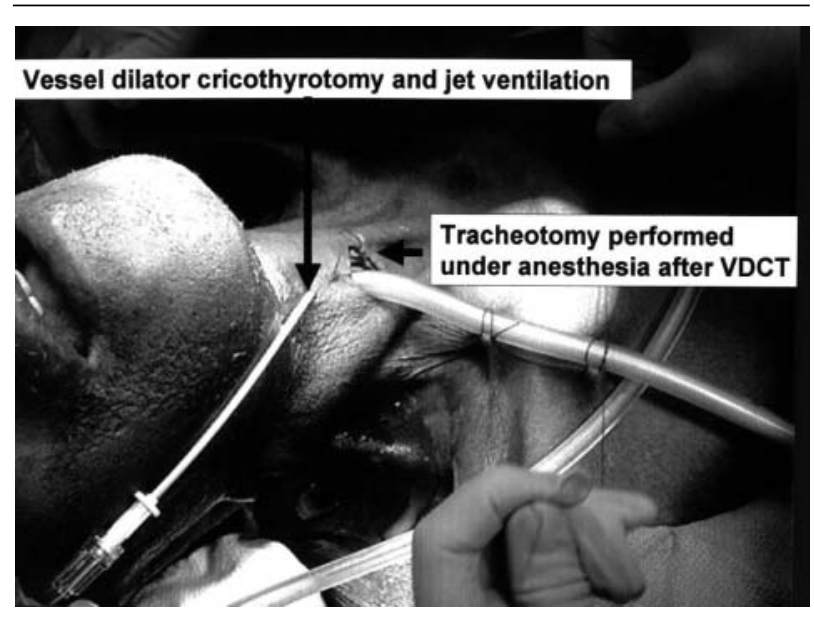

FIGURE After vessel dilator cricothyrotomy (VDCT), iv anesthesia is induced and oxygenation maintained with jet ventilation. A formal tracheotomy was performed under optimal conditions.

\section{Surgical procedures performed}

The following surgical procedures were performed on these 88 patients: 21 had a direct laryngoscopy and biopsy for diagnostic purposes. Fifteen of the 88 had a diagnostic procedure with airway debridement and subsequent successful extubation. Twenty-three patients underwent tracheotomy alone for long-term airway management and 29 of the 88 patients had a VDCT used as the induction method for an ultimate oncologic surgical procedure (tumour extirpation with tracheotomy left in place or creation of tracheostoma post laryngectomy).

\section{Complications}

No patient sustained a pneumothorax based upon clinical signs and symptoms (during and after anesthesia) and chest $x$-rays performed in the PACU. One patient developed bleeding from the cricothyrotomy puncture site, which resolved with applied pressure for one minute. Two patients who had significant coughing in the PACU, experienced sc emphysema over the anterior neck; this was self-limiting and did not interfere with any of the immediate surgical procedures, but did require unplanned hospital admissions for one night each.

There were no deaths or any significant morbidity resulting from the use of VDCT.

\section{Discussion}

Patients with large upper airway obstructing tumours can be very difficult to manage during attempts to 
secure the airway upon induction of general anesthesia. The clinical picture of these patients in extremis is well known to clinicians experienced in airway management. The typical patient is usually thin from malnutrition, comes to the operating room sitting upright on the stretcher holding the side rails with both hands, labouring with every breath. Inspiratory stridor, supraclavicular and intercostal in-drawing are frequent clinical signs. Associated problems include anxiety, restlessness, hypoxemia, hypercapnia, and in some severe cases, negative pressure pulmonary edema. ${ }^{5}$

Successful airway management of the patient with obstructing airway lesions is one of the greatest challenges for anesthesiologists. Adverse outcomes associated with difficult airway management are well illustrated in a report in the Closed Claims Analysis from the Committee on Professional Liability of the American Society of Anesthesiologists. Their findings show that adverse outcomes associated with respiratory events constitute the largest class of injury, with death and brain injury occurring in $85 \%$ of those cases. ${ }^{6,7}$

This review shows that in patients with supraglottic obstructive pathology, preemptive cricothyrotomy with jet ventilation apparatus can provide an oxygenation route directly into the tracheal lumen, bypassing the obstructing lesion. When correct placement of the catheter in the trachea is confirmed, a formal tracheotomy can then be performed below the cricothyrotomy puncture site (Figure) using iv agents to provide controlled anesthesia. Another option after cricothyrotomy is direct laryngoscopy, performed by the surgeon or the anesthesiologist, for endotracheal intubation. Although the supraglottic pathology often impairs visualization of the glottic aperture, the endoscopist can frequently cannulate the trachea with a small endotracheal tube or a bougie passed into the trachea through the egress site, identified by the appearance of bubbles. A third option is jet ventilation with $i v$ agents as the sole anesthetic technique while the surgeon creates an acceptable airway with an endoscopic microdebrider. ${ }^{8}$

Cricothyrotomy is not a new concept. ${ }^{9}, 10$ However, it is primarily used by most clinicians as a rescue or emergency technique and this recommendation is supported in the ASA algorithm on management of the difficult airway. ${ }^{1}$ Although cricothyrotomy is often a relatively simple procedure, abnormal anatomy and a crisis management scenario can magnify all possible difficulties. When preemptively placed under the best conditions possible, success is optimized.

We suggest that the $18-\mathrm{G}$ vessel dilator is optimal for jet ventilation. Although simple $i v$ catheters can be used for transtracheal jet ventilation, they are prone to kinking and compression. ${ }^{11}$ Further, their short length makes dislodgment a possible risk. ${ }^{12}$ It should be emphasized that a jet stream produced by a driving pressure of up to 55 psi through a $16 \mathrm{G}$ catheter delivers $500 \mathrm{~mL}$ of air per second. ${ }^{13}$ This gaseous volume delivered subcutaneously outside the tracheal lumen could collapse and totally obstruct the airway, converting a clinical challenge into an airway management disaster. There have been two fatalities at our institution when transtracheal jet ventilation through a $16 \mathrm{G}$ catheter was employed as a rescue maneuver for failed intubation in the emergency room. In both instances, the patients died from airway collapse when the catheters were dislodged from within the tracheal lumen. On the other hand, the vessel dilator is flexible, resists kinking, and has suitable length to be safely positioned in the tracheal lumen with minimal risk of dislodgment. It is not compressible and has an 18 G lumen, which is sufficient for successful jet ventilation. Large patients, such as our heaviest patient weighing $265 \mathrm{~kg}$, often require longer inflation times $(1.5-2 \mathrm{sec})$ at high pressures $(45-55 \mathrm{psi})$.

Most patients with supraglottic pathology causing significant airway obstruction that precludes standard induction of general anesthesia, are candidates for this VDCT. Exclusion criteria include: 1) inaccessibility of the cricothyroid membrane due to edema, obesity, thyroid pathology, or soft tissue extension of laryngotracheal tumour, 2) infection at the puncture site and 3 ) fixed flexion of the head and neck, as occurs with ankylosing spondylitis. Intratracheal pathology at the level of the cricothyroid membrane is a relative contraindication. Patients who have received head and neck radiation often have tissue that is severely indurated. If this has occurred at the cricothyrotomy puncture site in a patient with tumour recurrence obstructing the airway, a VDCT attempt is warranted.

Though this technique has proven to be efficacious and perhaps even life saving in patients with potentially lethal, obstructing airway lesions, both the surgeon and anesthesiologist must be mindful of potential complications. These include puncture of the posterior membranous wall of the trachea leading to $s c$ air or more serious sequelae such as mediastinitis. ${ }^{14} \mathrm{~A}$ key concern at the initiation of jet ventilation in patients with severely obstructing tumours is appropriate egress after each jet delivery so that pneumothorax and hypercapnia can be avoided. Careful monitoring of chest deflations and sounds of egress at the mouth or with a stethoscope at the larynx will help prevent these complications. 


\section{Conclusion}

In conclusion, patients with large obstructing glottic or supraglottic lesions requiring a surgical procedure under general anesthesia, may benefit from preemptive VDCT as the initial airway management procedure. With this catheter in place, jet ventilation with oxygen can protect the patient from lethal hypoxemia should total airway obstruction occur during attempts to secure the airway with other airway management techniques. Rather than employing transtracheal jet ventilation as a rescue technique during a "cannot intubate, cannot ventilate" crisis, ${ }^{15}$ VDCT, as described in this paper, can contribute to the successful management of the difficult airway scenario where supraglottic obstruction is a feature.

\section{References}

1 Caplan RA, Benumof JL, Berry FA, et al. Practice guidelines for management of the difficult airway. An updated report by the American Society of Anesthesiologists Task Force on Management of the Difficult Airway. Anesthesiology 2003; 98: 1269-77.

2 Gillespie MB, Eisele DW. Outcomes of emergency surgical airway procedures in a hospital-wide setting. Laryngoscope 1999; 109: 1766-9.

3 Yarrington CT, Fraser JP. Complications of tracheotomy. Arch Surg 1965; 91: 652-5.

4 Boyce JR, Peters G. Vessel dilator cricothyrotomy for transtracheal jet ventilation. Can J Anaesth 1989; 36: 350-3.

5 Lang SA, Duncan PG, Shephard DA, Ha HC. Pulmonary oedema associated with airway obstruction. Can J Anaesth 1990; 37: 210-8.

6 Caplan RA, Posner KL, Ward RJ, Cheney FW. Adverse respiratory events in anesthesia: a closed claims analysis. Anesthesiology 1990; 72: 828-33.

7 Schwartz DE, Matthay MA, Cohen NH. Death and other complications of emergency airway management in critically ill adults. Anesthesiology 1995; 82: 367-76.

8 Simoni P, Peters GE, Magnuson JS, Carroll WR. Use of the endoscopic microdebrider in the management of airway obstruction from laryngotracheal carcinoma. Ann Otol Rhinol Laryngol 2003; 112: 11-3.

9 Jacoby JJ, Hamelberg W, Ziegler CH, Flory FA, Jones JR. Transtracheal resuscitation. JAMA 1956; 162: 625-8.

10 Porter Reed J, Kemph JP, Hamelberg W, Hitchcock FA, Jacoby J. Studies with transtracheal artificial respiration. Anesthesiology 1954; 153: 28-41.

11 Carden E, Becker G, Hamood H. Percutaneous jet ventilation. Ann Otol Rhinol Laryngol 1976; 85: 652-5.

12 Weymuller EA, Pavlin EG, Paugh D, Cummings CW. Management of difficult airway problems with percuta- neous transtracheal ventilation. Ann Otol Rhinol Laryngol 1987; 96: 34-7.

13 Spoerel WE, Narayanan PS, Singh NP. Transtracheal ventilation. Br J Anaesth 1971; 43: 932-40.

14 Wong DT, McGuire GP. Subcutaneous emphysema following trans-cricothyroid membrane injection of local anesthetic. Can J Anesth 2000; 47: 165-8.

15 Benumof JL, Scheller MS. The importance of transtracheal jet ventilation in the management of the difficult airway. Anesthesiology 1989; 71: 769-78. 